\title{
The mitochondrial permeability transition, and oxidative and nitrosative stress in the mechanism of copper toxicity in cultured neurons and astrocytes
}

\author{
Pichili VB Reddy ${ }^{1}$, Kakulavarapu V Rama Rao ${ }^{1}$ and Michael D Norenberg ${ }^{1,2,3}$
}

Copper is an essential element and an integral component of various enzymes. However, excess copper is neurotoxic and has been implicated in the pathogenesis of Wilson's disease, Alzheimer's disease, prion conditions, and other disorders. Although mechanisms of copper neurotoxicity are not fully understood, copper is known to cause oxidative stress and mitochondrial dysfunction. As oxidative stress is an important factor in the induction of the mitochondrial permeability transition (mPT), we determined whether mPT plays a role in copper-induced neural cell injury. Cultured astrocytes and neurons were treated with $20 \mu \mathrm{M}$ copper and mPT was measured by changes in the cyclosporin A (CsA)-sensitive inner mitochondrial membrane potential $(\Delta \Psi \mathrm{m})$, employing the potentiometric dye TMRE. In astrocytes, copper caused a $36 \%$ decrease in the $\Delta \Psi \mathrm{m}$ at $12 \mathrm{~h}$, which decreased further to $48 \%$ by $24 \mathrm{~h}$ and remained at that level for at least $72 \mathrm{~h}$. Cobalt quenching of calcein fluorescence as a measure of mPT similarly displayed a $45 \%$ decrease at $24 \mathrm{~h}$. Pretreatment with antioxidants significantly blocked the copper-induced mPT by $48-75 \%$. Copper $(24 \mathrm{~h}$ ) also caused a $30 \%$ reduction in ATP in astrocytes, which was completely blocked by CsA. Copper caused death (42\%) in astrocytes by $48 \mathrm{~h}$, which was reduced by antioxidants (35-60\%) and CsA (41\%). In contrast to astrocytes, copper did not induce mPT in neurons. Instead, it caused early and extensive death with a concomitant reduction (63\%) in ATP by $14 \mathrm{~h}$. Neuronal death was prevented by antioxidants and nitric oxide synthase inhibitors but not by CsA. Copper increased protein tyrosine nitration in both astrocytes and neurons. These studies indicate that $\mathrm{mPT}$, and oxidative and nitrosative stress represent major factors in copper-induced toxicity in astrocytes, whereas oxidative and nitrosative stress appears to play a major role in neuronal injury.

Laboratory Investigation (2008) 88, 816-830; doi:10.1038/labinvest.2008.49; published online 30 June 2008

KEYWORDS: astrocytes; cell death; copper; mitochondrial permeability transition; neurons; oxidative stress

Copper is a critical element in the normal functioning of various enzymes, including $\mathrm{Cu} / \mathrm{Zn}$-superoxide dismutase, cytochrome c oxidase, ${ }^{1,2}$ dopamine- $\beta$ hydroxylase, and monoamine oxidase. ${ }^{3}$ Although copper is important in various metabolic processes, elevated copper concentrations in brain are neurotoxic. Copper has been implicated in the pathogenesis of various neurodegenerative disorders, including Alzheimer's disease, Parkinson's disease, familial amyotrophic lateral sclerosis, ${ }^{4-6}$ and prion disorders. ${ }^{7}$ The binding of copper to disease causing proteins, A- $\beta$ peptide, $\alpha$-synuclein, and prion proteins results in free radical production and associated oxidative stress (OS). ${ }^{4,7-9}$

Elevated copper levels play a primary role in Wilson's disease (hepatolenticular degeneration). Wilson's disease is an autosomal recessive inherited disorder, generally presenting toward the second decade of life. It is caused by the excessive accumulation of copper in the liver due to a defect in the copper transporting ATPase (ATP7B mutation). Copper accumulation in liver leads to hepatocyte necrosis, and ultimately its release into the vasculature. Copper is then taken up by the brain, where it accumulates primarily in the basal ganglia and cerebral cortex, resulting in degenerative changes in neurons and astrocytes. ${ }^{10-14}$

Although mechanisms of copper toxicity are not completely understood, OS has been implicated as an important factor. OS is mediated by the formation of free radicals (hydroxyl radicals) due to electron transfer occurring when copper shifts its valency from the divalent $\left(\mathrm{Cu}^{2+}\right)$ to

${ }^{1}$ Department of Pathology, University of Miami School of Medicine, Miami, FL, USA; ${ }^{2}$ Veterans Affairs Medical Center, University of Miami School of Medicine, Miami, FL, USA and ${ }^{3}$ Department of Biochemistry and Molecular Biology, University of Miami School of Medicine, Miami, FL, USA

Correspondence: Dr MD Norenberg, MD, Department of Pathology, University of Miami School of Medicine, PO Box 016960, Miami, FL 33101, USA.

E-mail: mnorenbe@med.miami.edu

Received 04 December 2007; revised 09 April 2008; accepted 09 April 2008 
monovalent $\left(\mathrm{Cu}^{+}\right)$state. ${ }^{15}$ As a result, copper has been shown to cause oxidative damage to proteins, lipids, and nucleic acids. ${ }^{16-20}$ Further, increased levels of hydroperoxides have been reported in a human glial cell line treated with excess copper. ${ }^{21}$ Copper has also been shown to cause a reduction in the activities of mitochondrial enzymes and depletion of ATP, and such changes were attenuated by pretreatment with antioxidants. ${ }^{22}$ Collectively, these findings support the involvement of OS and mitochondrial dysfunction in copper toxicity.

One potential consequence of OS is the induction of the mitochondrial permeability transition (mPT). The $\mathrm{mPT}$ is characterized by the opening of the permeability transition pore (PTP) localized in the inner mitochondrial membrane (IMM). The mPT results in increased permeability of IMM to protons, ions, and other solutes $\leq 1500 \mathrm{Da}$. This enhanced permeability of IMM results in a dissipation of the mitochondrial membrane potential $(\Delta \Psi \mathrm{m})$, defective oxidative phosphorylation, and reduced ATP production. ${ }^{23,24}$ The $\mathrm{mPT}$ is characteristically blocked by cyclosporin A (CsA). ${ }^{25}$

As copper is known to generate free radicals and to induce $\mathrm{OS},{ }^{21,22}$ we examined whether copper induces $\mathrm{mPT}$ in cultured astrocytes and neurons. Our results show that copper induces $\mathrm{mPT}$ in astrocytes but not in neurons and that it causes a delayed death in astrocytes, which was blocked by antioxidants, NOS inhibitors and CsA. In neurons, copper causes early and extensive cell death, which was not responsive to CsA, but was partially prevented by antioxidants and L-NAME.

\section{MATERIALS AND METHODS Astrocyte Cultures}

Primary cultured astrocytes were prepared from cerebral cortices of 1 day old rat pups by the method of Ducis et $a .^{26}$ Briefly, cortices were freed of meninges, minced and dissociated by trituration, passed through sterile nylon sieves, and then placed in Dulbecco's modified Eagle medium (DMEM) containing penicillin, streptomycin, and $15 \%$ fetal bovine serum. Approximately $0.5 \times 10^{6}$ cells were seeded in $35 \mathrm{~mm}$ culture plates and maintained at $37^{\circ} \mathrm{C}$ in an incubator equilibrated with $5 \% \mathrm{CO}_{2}$ and $95 \%$ air. After 2 weeks, cells were treated with $0.5 \mathrm{mM}$ dibutyryl cAMP to enhance astrocytic differentiation. ${ }^{27}$ Cultures consisted of $>98 \%$ astrocytes based on immunohistochemical staining with glial fibrillary acidic protein. Cells were 3-5 weeks old when used for experiments.

\section{Neuronal Cultures}

Cortical neurons were prepared by a modification of the method of Hertz and Matz. ${ }^{28}$ Cortices from 16- to 18-dayold rat fetuses were removed and placed in high glucose DMEM containing $25 \mathrm{mM} \mathrm{KCl}$ and $20 \%$ horse serum. The tissue was minced and mechanically dissociated with a pipette. Approximately $1-2 \times 10^{6}$ cells per $\mathrm{ml}$ were seeded onto poly-L-lysine-coated $35 \mathrm{~mm}$ culture dishes. In order to prevent astrocyte proliferation, cytosine arabinoside $(10 \mu \mathrm{M})$ was added for $24 \mathrm{~h}$ to the culture medium $48 \mathrm{~h}$ after the seeding of neurons. Cultures consisted of at least $98 \%$ neurons as determined by immunohistochemical staining for neurofilament protein. Experiments were performed on cultures that were 6-8 days old.

\section{Copper Treatment}

$\mathrm{CuSO}_{4}$ was employed as a source of $\mathrm{Cu}^{2+}$. To rule out the possibility that any effect of $\mathrm{CuSO}_{4}$ might be due to the sulfate anion rather than due to copper, all studies also examined the effect of $\mathrm{Na}_{2} \mathrm{SO}_{4}$ under similar conditions. $\mathrm{Na}_{2} \mathrm{SO}_{4}$ did not display changes in neurons and astrocytes on any of the parameters examined. Copper concentrations used in the present study were similar to those reported in the cerebrospinal fluid of patients with Wilson's disease..$^{29,30}$

\section{Light Microscopy}

Cell cultures were fixed in $10 \%$ buffered formalin for $30 \mathrm{~min}$ and washed twice with phosphate-buffered saline (PBS). Cells were then stained with May/Grunwald-Giemsa for 30 min and mounted with 50\% glycerol.

\section{Cell Death Assay}

Estimation of cell death was determined by the release of lactate dehydrogenase (LDH) using the method of Wroblewski and LaDue, ${ }^{31}$ as modified by Hazell et al. ${ }^{32}$ The amount of LDH released was calculated as the percentage of LDH activity in the medium $v s$ total LDH activity (that present in cells plus medium).

\section{Measurement of the Mitochondrial Membrane Potential}

The $\Delta \Psi \mathrm{m}$ was measured as described by Rao and Norenberg. ${ }^{33}$ At the end of the treatment period, the culture medium was removed, and cells were loaded with the potentiometric dye TMRE in DMEM, without phenol red or serum, at a final concentration of $50 \mathrm{nM}$ for $20 \mathrm{~min}$ so as to allow the dye to equilibrate between cytosolic and mitochondrial compartments. Cultures were examined with a Nikon Diaphot inverted fluorescent microscope equipped with multivariant fluorescent filters. The fluorescence emission was recorded at $590 \mathrm{~nm}$. To avoid mitochondrial leakage of TMRE due to photobleaching, cells were exposed to low fluorescent light intensity. Fluorescent intensities were then analyzed using the Sigma Scan Pro image quantitation software (Sigma, St Louis, MO, USA). Total number of pixels was quantified on a gray scale (0-255) and the average pixel (fluorescent intensity) value in each image containing an approximately equal number of cells, was obtained and expressed as the mean \pm s.e.m. of the total fluorescence intensity derived from at least 15 random image fields in each group. The selection of fields was achieved by systematically moving the microscope platform by $5 \mathrm{~mm}^{2}$ in all four directions. The investigator was 'blinded' as to whether 
control or treated plates were being examined. Arbitrary TMRE fluorescent intensities were expressed as a percent fluorescence change over control.

To exclude the possibility that changes in the plasma membrane potential influenced TMRE loading, astrocyte cultures were exposed to different concentrations $(10-100 \mathrm{mM})$ of $\mathrm{KCl}$ for $30-45 \mathrm{~min}$ to depolarize plasma membrane. Untreated and $\mathrm{KCl}$-treated cells were then incubated with $50 \mathrm{nM}$ TMRE $(20 \mathrm{~min}) . \mathrm{KCl}$ had no effect on mitochondrial TMRE fluorescence levels in astrocytes and neurons as compared to untreated cells, indicating that changes in the plasma membrane potential did not influence the $\Delta \Psi \mathrm{m}$ measurements.

\section{Measurement of the Mitochondrial Permeability Using Calcein Fluorescence}

As an additional measure of $\mathrm{mPT}$, calcein fluorescence studies were carried out following the method of Petronilli et $a l,{ }^{34}$ as modified by Rao and Norenberg. ${ }^{33}$ This method allows one to directly visualize permeability changes in mitochondria in situ. Upon addition of calcein/acetoxymethyl ester, the dye enters the cells and becomes fluorescent on de-esterification. Co-loading of cells with cobalt chloride quenches the fluorescence in the cell, except in mitochondria, as cobalt is impermeable across the mitochondrial membrane. However, during induction of $\mathrm{mPT}$ and opening of PTP, cobalt enters mitochondria resulting in a quenching of fluorescence. The extent of such quenching represents a measure of mPT.

At the end of copper treatment, cultures were washed three times with Hanks' balanced salt solution (HBSS; $144 \mathrm{mM}$ $\mathrm{NaCl}, 10 \mathrm{mM}$ HEPES, $2 \mathrm{mM} \mathrm{CaCl}_{2}, 1 \mathrm{mM} \mathrm{MgCl}_{2}, 5 \mathrm{mM} \mathrm{KCl}$,

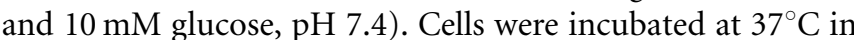
fresh HBSS containing calcein/acetoxymethyl ester $(1 \mu \mathrm{M})$ and cobalt chloride $(1 \mathrm{mM})$ for $20 \mathrm{~min}$. Following cobalt treatment, cultures were washed with HBSS, and images were collected within $10-15 \mathrm{~min}$ as described above. To confirm that the calcein fluorescence is indeed localized to mitochondria, cells were loaded with the mitochondrial specific fluorescent dye MitoTracker Red CMXRos (MitoRed; $100 \mathrm{nM}$ ) for $5 \mathrm{~min}$ and images of both calcein and MitoRed were individually captured. The images were then merged and the extent of colocalization of fluorescence was assessed. We observed $>90 \%$ colocalization of calcein fluorescence with that of MitoRed in astrocytes (Figure 1), indicating that calcein is largely localized in mitochondria.

\section{Measurement of ATP}

Levels of ATP in neurons and astrocytes were measured using a bioluminescence assay kit (Sigma) following the manufacture's protocol. Briefly, after aspirating the medium, cultures were washed twice with ice-cold PBS and lysed in $0.1 \%$ Triton X100 containing $50 \mu \mathrm{M}$ EGTA. To $0.1 \mathrm{ml}$ of cell lysate, $1 \mathrm{ml}$ of the ATP assay mixture was added, incubated for $3 \mathrm{~min}$, and the luminescence measured with a luminometer (Turner Biosystems, Sunnyvale, CA, USA). The concentration of ATP in each sample was calculated from the ATP standard curve and expressed as percent ATP/mg protein.

\section{Western Blots for Protein Tyrosine Nitration}

Neural cultures were solubilized in lysis buffer $(50 \mathrm{mM}$ Tris, $150 \mathrm{mM} \mathrm{NaCl}, 2 \%$ sodium dodecyl sulfate (SDS); $1 \% \mathrm{NP}-40$; $0.5 \%$ sodium deoxycholate ( $\mathrm{pH} 8.0$ ), and a protease inhibitor mixture). Lysates were centrifuged at $12000 \mathrm{~g}$ for $12 \mathrm{~min}$ and protein levels in the supernatant were measured by the BCA method (Thermo Scientific, Rockford, IL, USA). Equal amounts of protein $(30 \mu \mathrm{g}$ of total protein per lane) were subjected to SDS-PAGE and electrophoretically transferred to polyvinylidene difluoride membranes at $100 \mathrm{~V}$ for $2 \mathrm{~h}$. Following blocking with 5\% BSA (in 3\% Tris-buffered saline and $0.1 \%$ Tween-20) for $2 \mathrm{~h}$ at RT, the membranes were incubated with anti-nitrotyrosine (1:500) or anti- $\alpha$-tubulin $(1: 1000)$ at $4^{\circ} \mathrm{C}$ overnight and subsequently with HRP-conjugated secondary antibodies (1:2000; $2 \mathrm{~h}$ at RT). Membranes were visualized using ECL. Optical density of the bands was measured with the Chemi-Imager digital imaging system (Alpha Innotech, San Leandro, CA, USA), and results were quantified with Sigma Scan Pro as a proportion of the signal of a housekeeping protein band ( $\alpha$-tubulin).

\section{Western Blots for Protein Carbonyls}

Protein carbonyls in both neurons and astrocytes were determined by immunoblots using a commercially available protein carbonyl detection kit (OxyBlot; Chemicon, Temecula, CA, USA). At the end of treatment, media was aspirated, cultures washed twice with ice-cold PBS, and extracted into lysis buffer. Cell lysates were centrifuged at $12000 \mathrm{~g}$ for $12 \mathrm{~min}$ and the supernatants were used to determine protein carbonyl content. Supernatants containing equal amounts of protein were derivatized with 2,4-dinitrophenylhydrazine (DNPH), subjected to SDS-PAGE followed by immunoblotting with anti-DNPH antibody (1:300), and the membranes visualized using ECL.

\section{Statistical Analysis}

Experiments were performed in triplicate or quadruplicate from cultures derived from 3 to 4 separate seedings. The data were subjected to analysis of variance followed by post hoc Neuman-Keuls multiple test. Data were represented as mean \pm s.e.m.

\section{RESULTS}

\section{Effects of Copper on Astrocytes}

Giemsa-stained astrocyte cultures did not show morphological abnormalities by light microscopy at $24 \mathrm{~h}$ after copper treatment $(20 \mu \mathrm{M})$. After $48 \mathrm{~h}$, astrocytes exhibited multiple areas of necrosis characterized by the presence of pyknotic nuclei, cytoplasmic disintegration and cell loss (Figure 2). Such changes were exacerbated by $72 \mathrm{~h}$ (data not shown). 

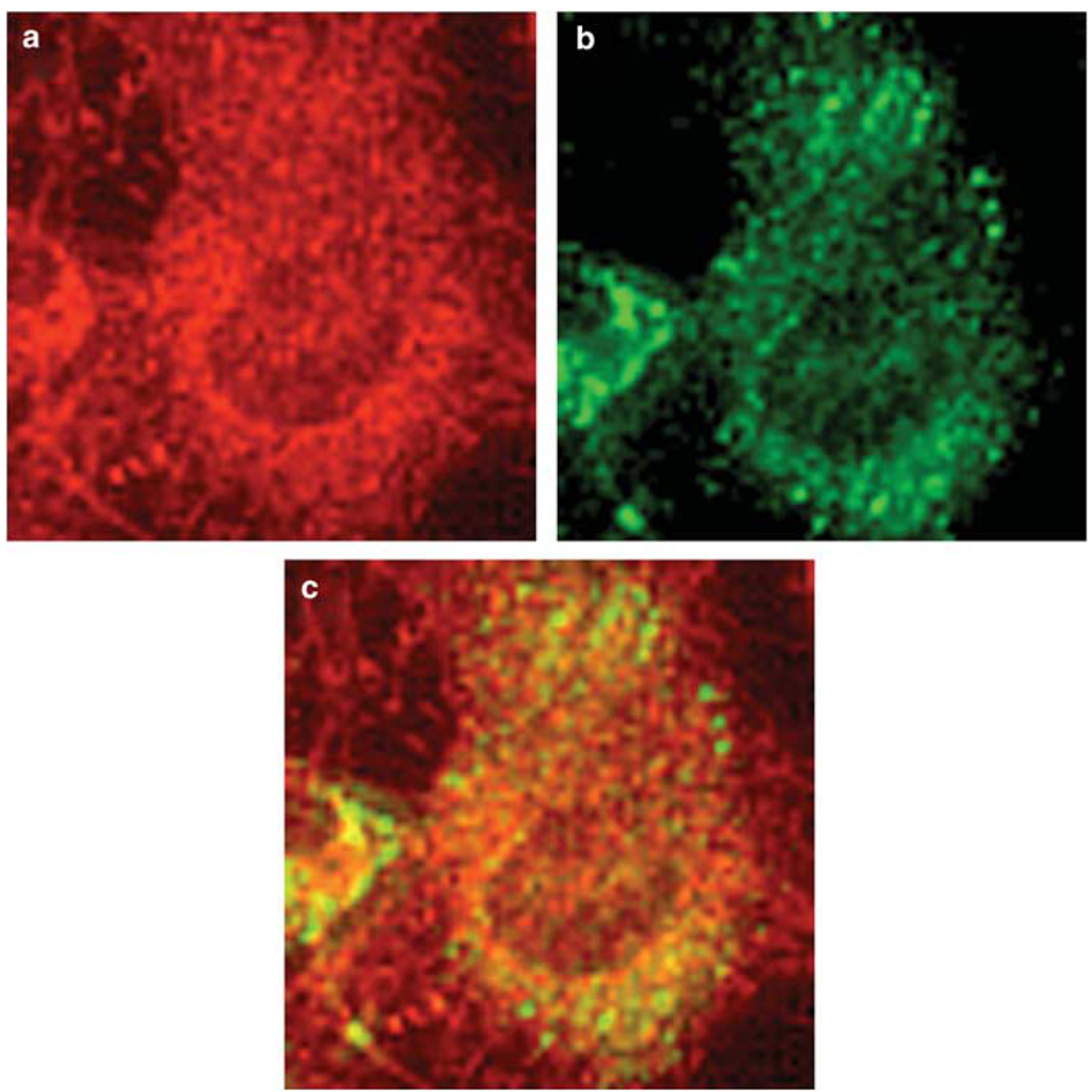

Figure 1 Representative fluorescent images of control cultured astrocytes displaying mitochondrial colocalization of calcein and MitoTracker red fluorescence. (a) Fluorescence image of the MitoTracker red; (b) calcein; (c) merged images of (a) and (b) showing mitochondrial colocalization of calcein.

Consistent with cytopathological abnormalities, treatment of astrocytes with $20 \mu \mathrm{M}$ copper for $24 \mathrm{~h}$ did not show significant changes in LDH release (a measure of cell death), whereas a $42 \%(P<0.01) \mathrm{LDH}$ release was observed at $48 \mathrm{~h}$, which further increased at $72 \mathrm{~h}(56 \% ; P<0.01)$. LDH release in controls was $8 \pm 2 \%$ (Figure 3 ).

To examine whether copper induces $\mathrm{mPT}$, astrocytes were treated with copper $(20 \mu \mathrm{M})$ for varying time periods, and changes in the $\Delta \Psi \mathrm{m}$ were determined by TMRE fluorescence. Copper caused a significant dissipation of the $\Delta \Psi \mathrm{m}$ at $12 \mathrm{~h}$ (36\%, $P<0.05)$, which further decreased to $48 \%(P<0.05)$ by $24 \mathrm{~h}$ (Figures $4 \mathrm{a}$ and b). Such decrease in the $\Delta \Psi \mathrm{m}$ was completely blocked by CsA $(1 \mu \mathrm{M})$. To rule out the possibility that the effect of CsA might be due to its calcineurin blocking effect rather than its mPT inhibitory action, we examined the effect of FK506, which like CsA has calcineurin inhibitory effects but has no influence on mPT. In contrast to CsA, FK506 did not block the copper-induced dissipation of the $\Delta \Psi \mathrm{m}$, confirming that copper induced $\mathrm{mPT}$ (Figures $4 \mathrm{~b}$ ).

To further establish the induction of $\mathrm{MPT}$ by copper, changes in mitochondrial permeability were examined using mitochondrial calcein fluorescence after quenching with cobalt. Similar to TMRE, copper caused a $45 \%$ decrease in calcein fluorescence at $24 \mathrm{~h}$, which was completely blocked by CsA (Figure 5a and b); FK506 had no effect on calcein florescence (Figure 5b). Together with the TMRE findings, the results indicate that copper induces $\mathrm{mPT}$ in astrocytes.

To determine the potential role of oxidative/nitrosative stress in the mediation of mPT by copper (Figure 6a), astrocytes were pretreated $(15 \mathrm{~min})$ with various antioxidants and nitric oxide synthase (NOS) inhibitors, and the cells were then exposed to copper $(20 \mu \mathrm{M})$ for $24 \mathrm{~h}$. Desferroxamine (DFX; 75\%; $P<0.01$ ), $N(\mathrm{G})$-nitro-L-arginine methyl ester (L-NAME; 64\%; $P<0.01$ ), aminoguanidine (inducible NOS, iNOS inhibitor; $56 \% ; P<0.01$ ), and $N$-t-butyl- $\alpha$-phenylnitrone $(\mathrm{PBN} ; 56 \% ; \quad P<0.05)$ significantly attenuated the copper-induced dissipation of $\Delta \Psi \mathrm{m}$. Vitamin $\mathrm{E}$ $(\alpha$-tocopherol) and 7 -nitroindazole (constitutive NOS, cNOS inhibitor) did not block the copper-induced mPT (Figure 6a and b).

As induction of $\mathrm{mPT}$ is known to result in mitochondrial bioenergetic failure, which when severe can result in cell death, ${ }^{23}$ we examined the effect of copper on ATP levels in 

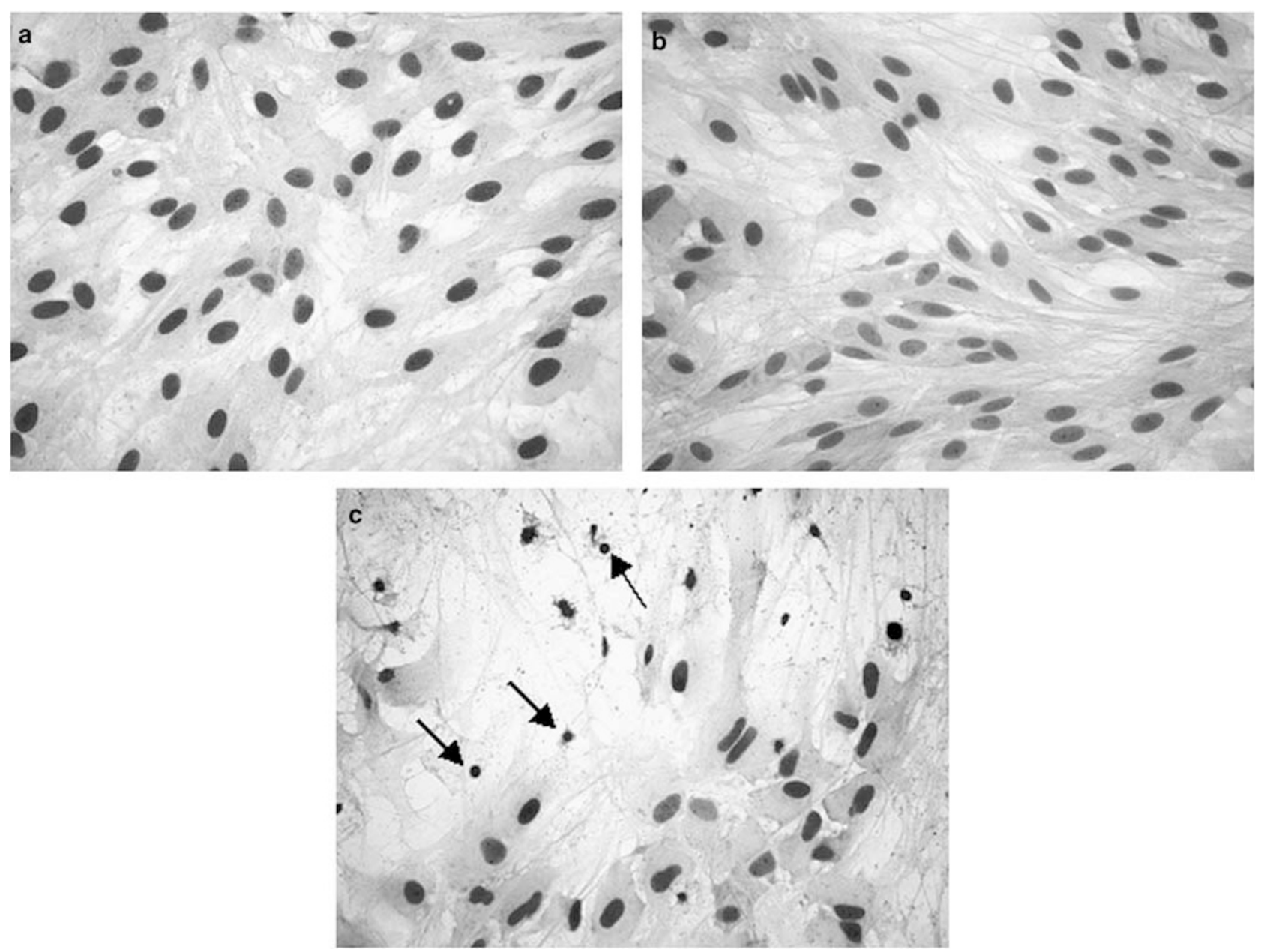

Figure 2 Photomicrographs of cultured astrocytes stained with May/Grunwald-Geimsa. (a) Control astrocytes show intact cell bodies containing a network of cytoplasmic processes. (b) Cultured astrocytes treated with $\mathrm{CuSO}_{4}(20 \mu \mathrm{M})$ for $24 \mathrm{~h}$ are similar to controls. (c) Astrocytes treated with $\mathrm{CuSO}_{4}$ for $48 \mathrm{~h}$ shows a focal area of cellular disintegration, nuclear pyknosis (arrows), and cell loss.

cultured astrocytes. Exposure of astrocytes to copper $(20 \mu \mathrm{M})$ for $24 \mathrm{~h}$ resulted in a significant reduction $(32 \% ; P<0.05)$ in ATP levels, which was completely blocked by pretreatment with CsA (Table 1). To examine whether mPT contributes to astrocyte death, cultures were pretreated with CsA $(1 \mu \mathrm{M})$ and $\mathrm{LDH}$ release was examined $48 \mathrm{~h}$ after copper treatment. CsA significantly attenuated astrocyte death by $41 \%$ $(P<0.05)$, whereas FK506 had no effect (Figure 7).

To examine whether copper exerts oxidative and/or nitrosative damage to astrocytes, levels of protein carbonyls and protein tyrosine nitration (PTN) were measured at 24 and $48 \mathrm{~h}$. Copper caused only a minimal effect on protein carbonylation at both 24 and $48 \mathrm{~h}$ (data not shown). By contrast, copper resulted in a significant increase in PTN of several proteins in the range of $60-85 \mathrm{kDa}$. Such PTN by copper was significantly blocked by pretreatment with CsA (Figure 8).

We then examined the involvement of oxidative/nitrosative stress in copper-induced astrocyte death, by determining the effect of antioxidants and inhibitors of NOS. Antioxidants significantly blocked astrocyte death to a variable degree: DFX (49\%; $P<0.01)$, PBN (42\%; $P<0.05)$, and vitamin $\mathrm{E}$ $(36 \% ; P<0.05)$. Likewise, L-NAME and aminoguanidine significantly blocked astrocytes death by 61 and 53\%, respectively. 7-NI had no effect (Figure 7).

\section{Effects of Copper on Neurons}

Exposure of cultured neurons to copper $(20 \mu \mathrm{M})$ resulted in significant neuronal death by $14 \mathrm{~h}$ (Figure 9). Early neuronal death was also documented by LDH release $(75 \% P<0.01)$. Even at $10 \mu \mathrm{M}$, copper caused a $35 \%(P<0.05)$ increase in neuronal $\mathrm{LDH}$ release by $14 \mathrm{~h}$, which was further increased $(68 \%, P<0.01)$ by $18 \mathrm{~h}$ (Figure 10$). \mathrm{LDH}$ release in control cultures was $16 \pm 3 \%$.

To examine whether copper also induces $\mathrm{mPT}$ in neurons, cells were exposed to $\mathrm{CuSO}_{4}(10$ and $20 \mu \mathrm{M})$ and examined for changes in the TMRE fluorescence. Unlike astrocytes, no changes were observed in TMRE fluorescence in neurons at any time point after copper exposure (potential changes in TMRE fluorescence were carefully monitored for up to $18 \mathrm{~h}$ ). 


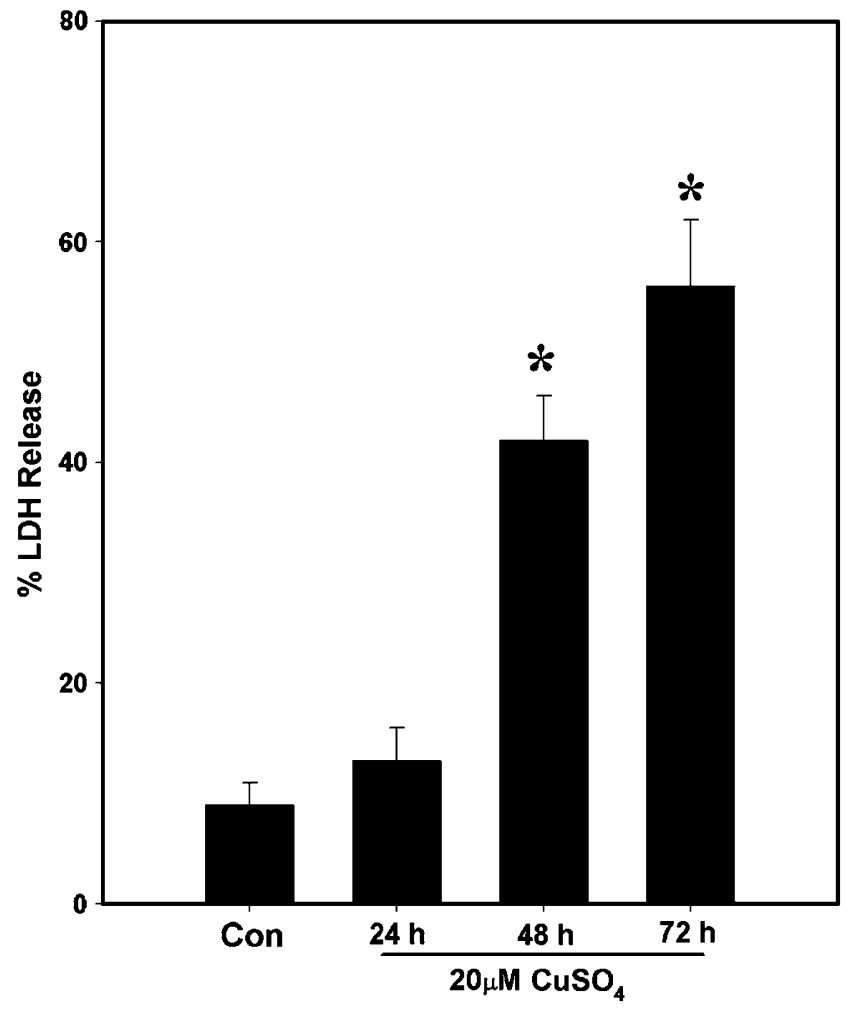

Figure 3 Time course of $\mathrm{LDH}$ release in cultured astrocytes treated with $\mathrm{CuSO}_{4}(20 \mu \mathrm{M}) .{ }^{*} P<0.01$ vs control.
Similarly, no change in mitochondrial cobalt quenching of calcein fluorescence was ever detected prior to neuronal death (Figures 11 and 12). Moreover, neither the loss of TMRE and calcein fluorescence, nor neuronal death was blocked by CsA $(1 \mu \mathrm{M})$. Altogether, these results indicate that copper causes extensive cell injury/death in neurons without an obvious induction of $\mathrm{mPT}$.

We then examined whether oxidative/nitrosative stress plays a role in copper-induced neuronal death by pretreating (15 min) cultures with antioxidants (DFX, PBN, vitamin E) as well as NOS inhibitors (L-NAME, aminoguanidine, and 7 -nitroindazole) and then exposing the cells to $10 \mu \mathrm{M}$ copper for $18 \mathrm{~h}$. Neuronal death was blocked by antioxidants and NOS inhibitors to a differential degree: DFX $(52 \% ; P<0.01)$, vitamin E (42\%; $P<0.05)$, and PBN $(24 \% ; P<0.05)$. Similarly L-NAME and aminoguanidine blocked neuronal death by 49 and $42 \%$ respectively $(P<0.01)$, whereas 7-nitroindazole did not have a protective effect (Figure 13).

Similar to astrocytes, copper ( $14 \mathrm{~h}$ ) had only a minimal effect on protein carbonyl formation in neurons (data not shown), whereas a significant increase in PTN was observed (Figure 14).

\section{DISCUSSION}

This study demonstrates that exposure of primary cultures of rat astrocytes to high concentrations of $\mathrm{CuSO}_{4}$ induced mPT
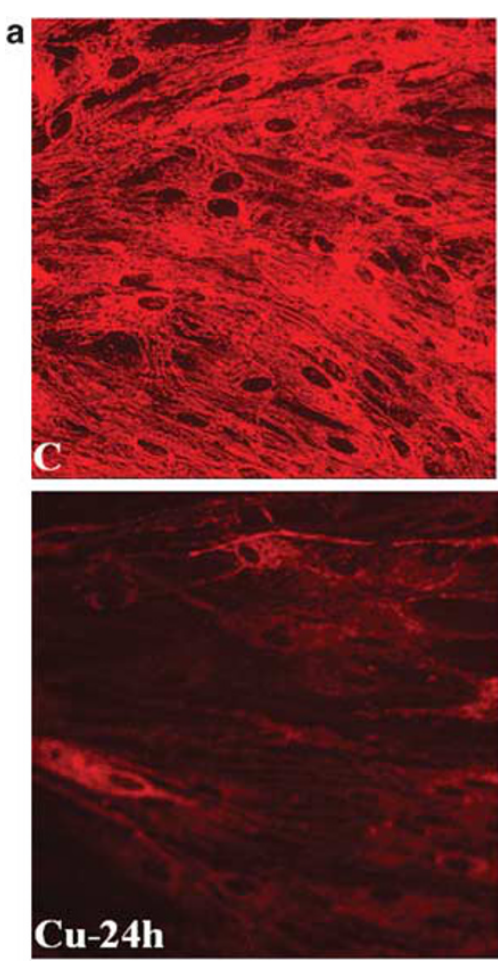
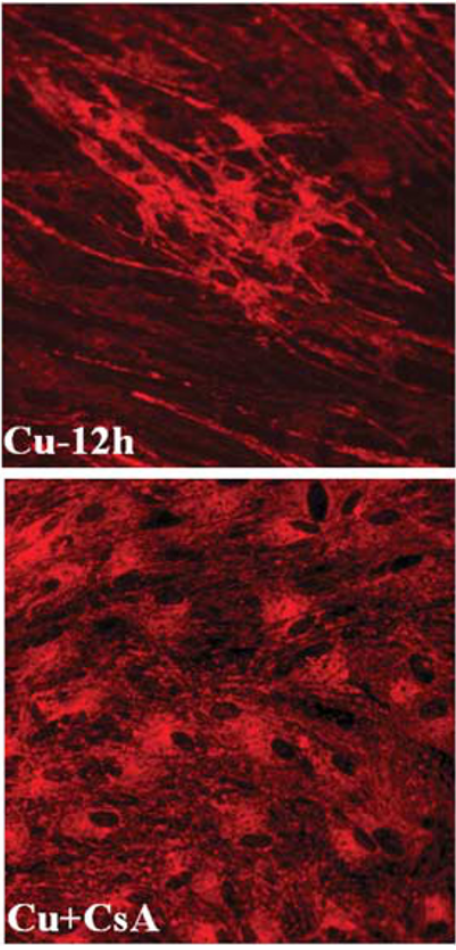

b

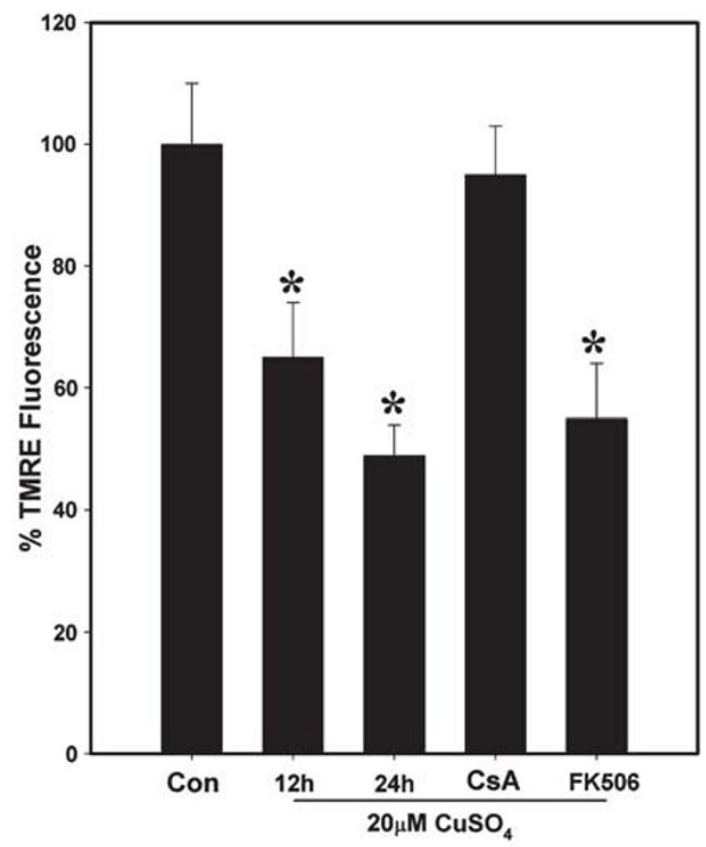

Figure 4 Effect of copper on the dissipation of the $\Delta \Psi \mathrm{m}$ in cultured astrocytes. (a) Control astrocytes show bright TMRE fluorescence indicating polarized mitochondria. Cultured astrocytes treated with $20 \mu \mathrm{M} \mathrm{CuSO}_{4}$ for 12 and $24 \mathrm{~h}$ display a progressive dissipation of the $\Delta \Psi \mathrm{m}$. Pretreatment of cultured astrocytes with $\mathrm{CsA}$ completely blocked the $\mathrm{CuSO}_{4}$-induced dissipation of the $\Delta \Psi \mathrm{m}$, consistent with mPT. (b) Quantification of fluorescent images. CsA completely blocked copper-induced dissipation of the $\Delta \Psi \mathrm{m}$, whereas FK506 had no effect. ${ }^{\star} P<0.05$ vs control. 

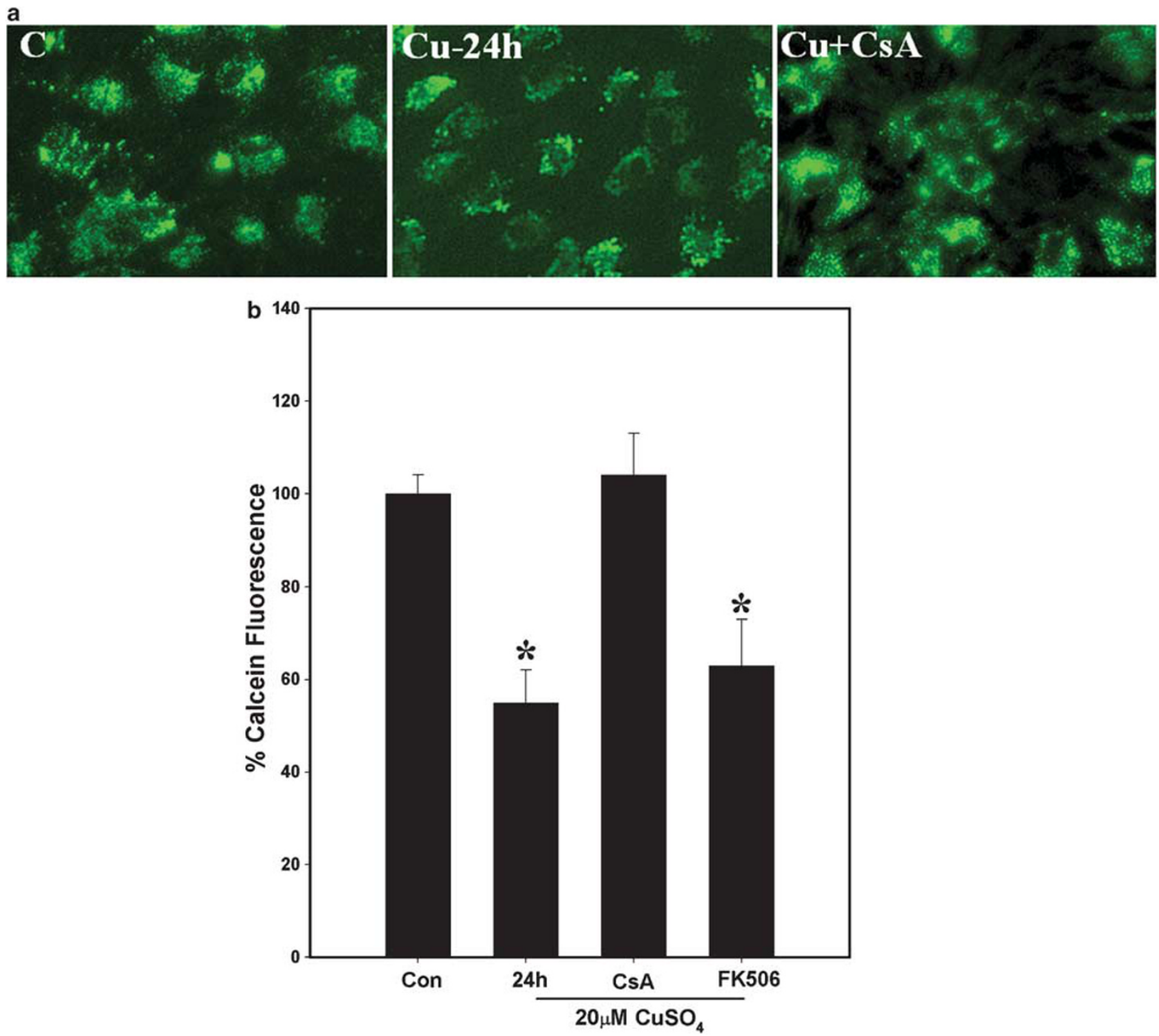

Figure 5 Effect of copper on the mitochondrial permeability transition in cultured astrocytes. (a) Control astrocytes show bright fluorescence, whereas astrocytes treated with $\mathrm{CuSO}_{4}$ for $24 \mathrm{~h}$ display a reduction in calcein fluorescence. Pretreatment of astrocytes with $\mathrm{CsA}_{\mathrm{A}}$ blocked the CuSO${ }_{4}$-induced loss of fluorescence. (b) Quantification of fluorescent images. CsA completely blocked the decrease in calcein fluorescence caused by copper, whereas FK506 had no effect. ${ }^{*} P<0.01$ vs control.

as demonstrated by a significant dissipation of the $\Delta \Psi \mathrm{m}$ and decreased mitochondrial calcein fluorescence after quenching with cobalt. These changes were completely blocked by CsA, and not by FK 506, indicating the involvement of $\mathrm{mPT}$ in the mechanism of copper toxicity. The copper-induced mPT was significantly blocked by antioxidants and NOS inhibitors. Additionally, copper resulted in a 30\% reduction in ATP levels, which was also completely blocked by CsA. Although no astrocyte death was evident at $24 \mathrm{~h}$ after copper treatment, significant death was observed at $48 \mathrm{~h}$, which was significantly prevented by CsA, antioxidants, and NOS inhibitors. Copper showed minimal changes in protein oxidation whereas an increased PTN was evident in astrocytes. In neurons, on the other hand, $\mathrm{mPT}$ was not identified at any time point.
Instead, neurons showed early and extensive cell death with a concomitant reduction (63\%) in ATP levels. Neuronal death was prevented by antioxidants and NOS inhibitors but not by CsA. Oxidation of proteins and PTN patterns in neurons were similar to that of astrocytes.

Although mechanisms for induction of mPT in astrocytes by copper are not completely understood, copper is known to cause OS, a factor well known to induce mPT. ${ }^{35-37}$ The OS-induced $\mathrm{mPT}$ involves oxidation of the adenine nucleotide translocase, a protein generally considered to be a key component of the PTP complex. ${ }^{35}$ Our study demonstrates the ability of PBN (a spin trapping agent) and DFX (iron chelator) to block the copper-induced $\mathrm{mPT}$, strongly suggesting an important role of OS in the induction of $\mathrm{mPT}$. 

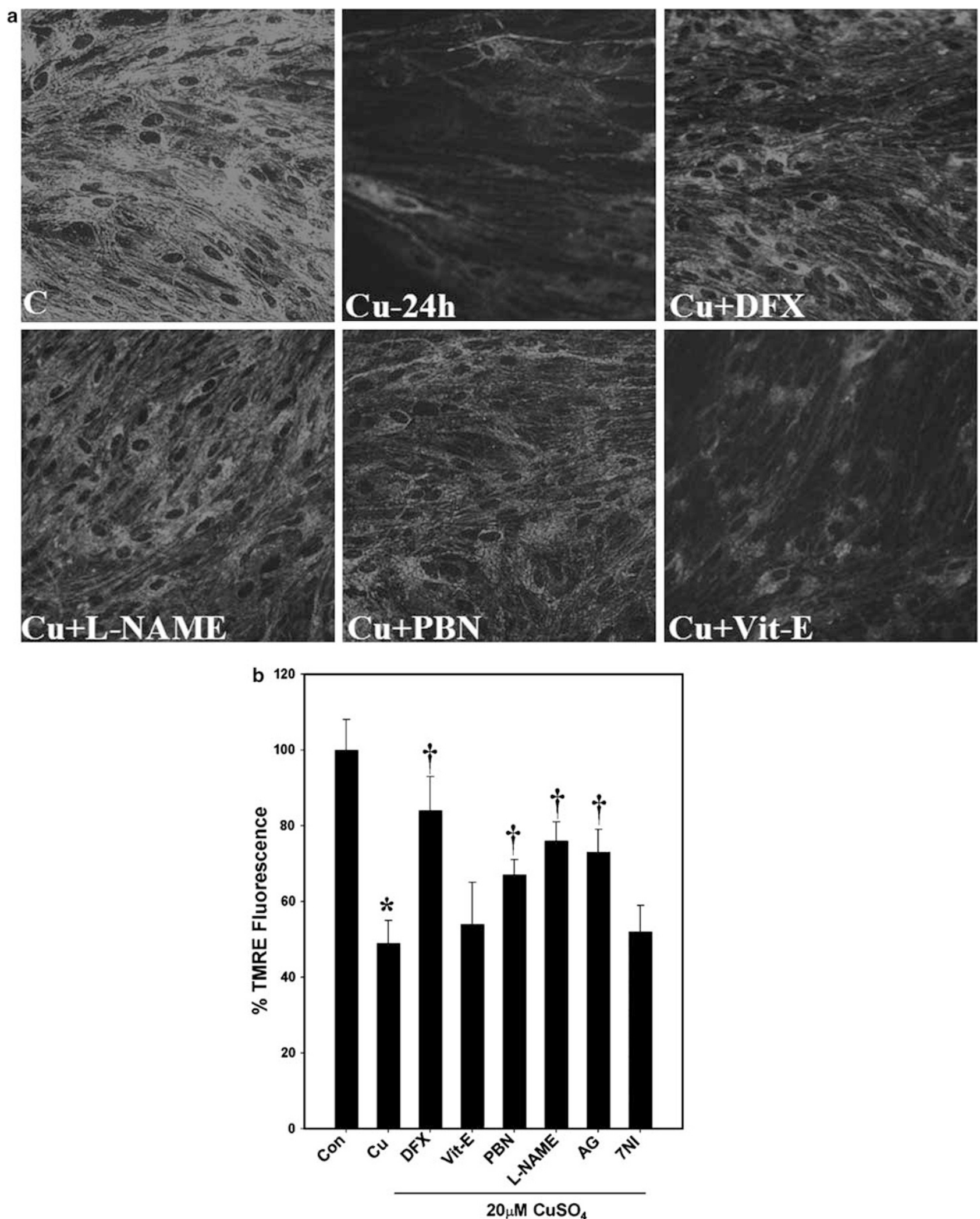

Figure 6 Effect of antioxidants and NOS inhibitors on the copper-induced mPT. Cells were treated with $\mathrm{CuSO}_{4}$ for $24 \mathrm{~h}$. (a) Control astrocytes show bright fluorescence, whereas cells treated with $\mathrm{CuSO}_{4}$ show reduced fluorescence. Pretreatment of astrocytes with antioxidants: (DFX (40 $\left.\mu \mathrm{M}\right), \mathrm{L}-\mathrm{NAME}(500 \mu \mathrm{M})$, and PBN $(250 \mu \mathrm{M}))$ significantly attenuated the copper-induced dissipation of the $\Delta \Psi \mathrm{m}$. Vitamin $\mathrm{E}(\mathrm{Vit}-\mathrm{E})$ did not have a protective effect. Additionally, aminoguanide (AG: $200 \mu \mathrm{M}$ ) significantly blocked $\Delta \Psi \mathrm{m}$ dissipation after copper treatment, whereas 7-nitroindazole (7-NI, $50 \mu \mathrm{M})$ did not. (b) Quantification of TMRE fluorescence intensity. ${ }^{\star} P<0.01$ vs control and ${ }^{\dagger} P<0.01-0.05$ vs $\mathrm{CuSO}_{4}$. 
Table 1 Effect of copper on ATP content in cultured astrocytes and neurons

\begin{tabular}{lccc}
\hline Cell type & Control (\%) & Copper (\%) & Copper+CsA (\%) \\
\hline Astrocytes & 100 & $78^{*}$ & $94^{* *}$ \\
Neurons & 100 & $37^{*}$ & 40 \\
\hline
\end{tabular}

There was a greater degree of ATP depletion in neurons compared to astrocytes.

${ }^{\star} P<0.05-0.01$ vs control; ${ }^{*} P<0.05$ vs copper.

CsA, cyclosporin A.

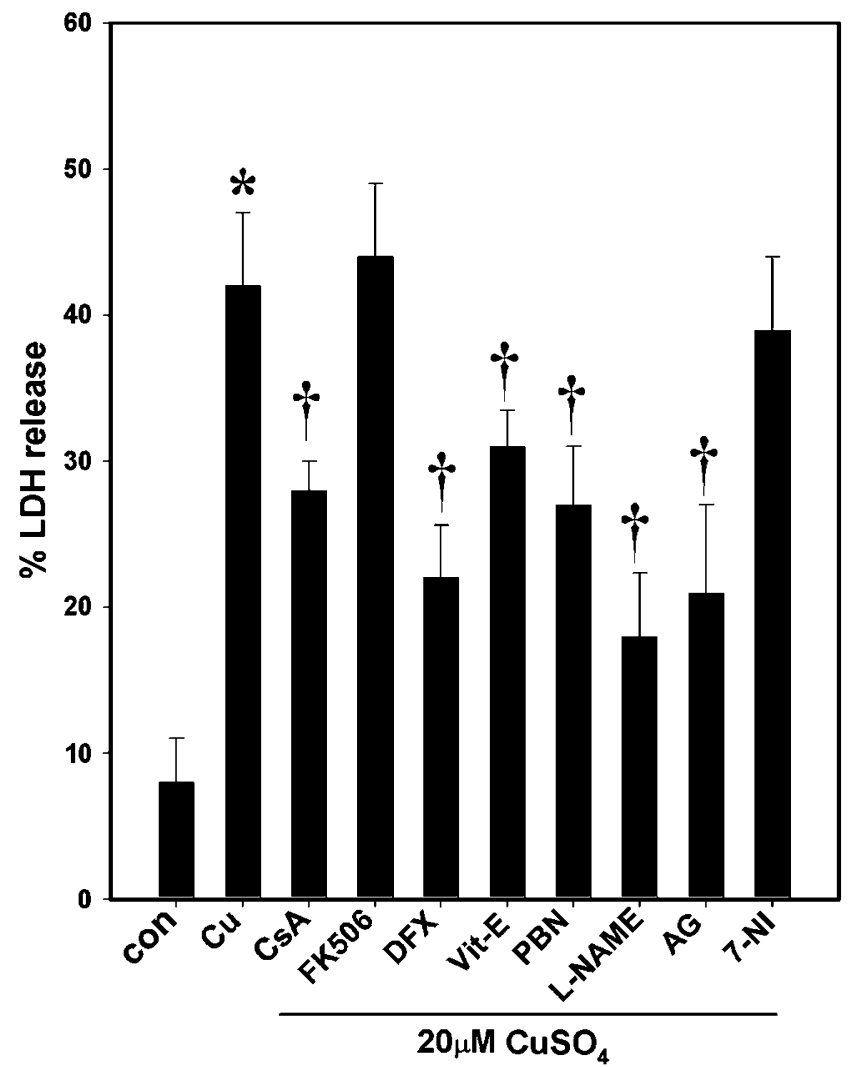

Figure 7 Effect of antioxidants and nitric oxide synthase inhibitors on copper-induced cell death in cultured astrocytes as determined by the extent of $\mathrm{LDH}$ release. Cells were treated with $\mathrm{CuSO}_{4}$ for $48 \mathrm{~h}$. Astrocytes treated with $\mathrm{CuSO}_{4}$ alone showed $42 \% \mathrm{LDH}$ release. Pretreatment of cultures with antioxidants or CSA significantly reduced the extent of $\mathrm{LDH}$ release. ${ }^{\star} P<0.01$ vs control and ${ }^{\dagger} P<0.01-0.05$ vs $\mathrm{CuSO}_{4}$. $7-\mathrm{NI}$ and FK506 had no effect.

Vitamin E ( $\alpha$-tocopherol) did not block mPT in astrocytes, although it did significantly inhibit cell death (see below). Such variable effects by vitamin $\mathrm{E}$ might be due to differences in the time course of induction of $\mathrm{mPT}$ and the occurrence of cell death. $\mathrm{mPT}$ was induced as early as $12 \mathrm{~h}$, whereas astrocytic death was detected only at $48 \mathrm{~h}$. It is therefore possible that lipid peroxidation by copper might be a delayed event

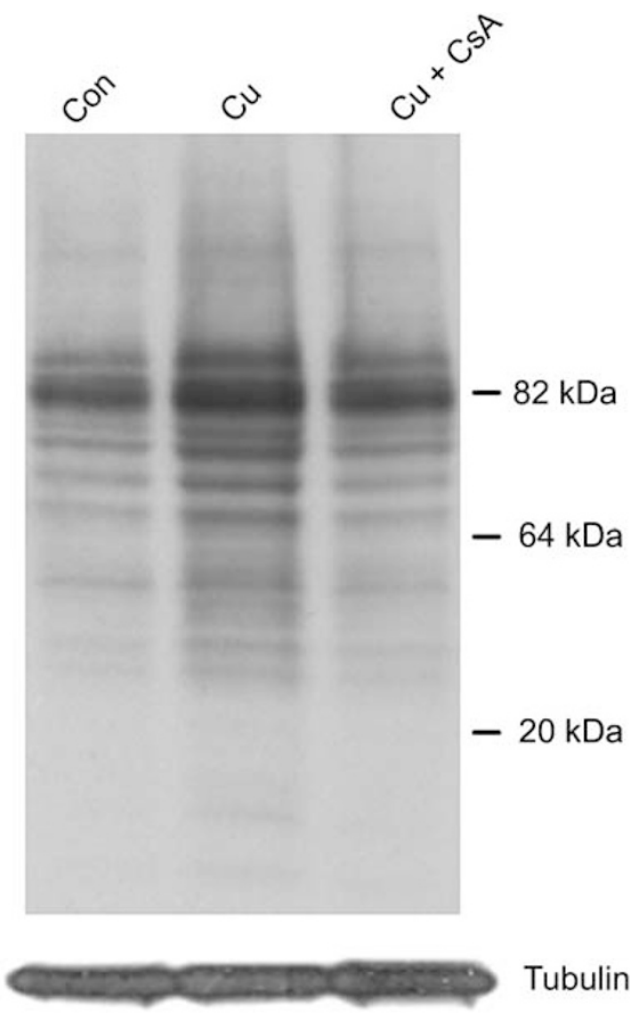

Figure 8 Effect of copper on protein tyrosine nitration in cultured astrocytes. Copper caused increased tyrosine nitration of proteins in the range of $32-85 \mathrm{kDa}$.

that is important in astrocytic death, but may not be critical for induction of mPT.

Copper treatment has been shown to increase nitric oxide (NO) levels by upregulating iNOS, ${ }^{38}$ and NO is known to induce $\mathrm{mPT}^{39,40}$ The observation that L-NAME significantly blocked the copper-induced mPT suggests NO is one factor responsible for $\mathrm{mPT}$. Moreover, inhibition of $\mathrm{mPT}$ by aminoguanidine, but not 7-nitroindazole, suggests the involvement of iNOS in mPT induction.

Although our investigation demonstrates that copper induces $\mathrm{mPT}$ in cultured astrocytes, an earlier study failed to identify it, ${ }^{41}$ although in that study copper potentiated the dissipation of $\Delta \Psi \mathrm{m}$ caused by menadione, rotenone, and $\mathrm{H}_{2} \mathrm{O}_{2}$. A likely explanation for this discrepancy may be that the investigators employed very high concentration of copper $(100 \mu \mathrm{M})$ for only a short time period $(40 \mathrm{~min})$. Our study was carried out for $12-24 \mathrm{~h}$ employing a lower concentration of copper $(20 \mu \mathrm{M})$, suggesting that longer exposure and lower concentrations are required for $\mathrm{mPT}$ to occur in astrocytes. Induction of $\mathrm{mPT}$ by low concentrations of copper $(4-10 \mu \mathrm{M})$ has also been reported in isolated mitochondria derived from rat kidney, ${ }^{42}$ and in primary cultures of trout hepatocytes. ${ }^{43}$

Copper did not result in astrocyte death by $24 \mathrm{~h}$ consistent with a recent report by Chen et al. ${ }^{44}$ On the other hand, copper caused a moderate and delayed cell death by $48 \mathrm{~h}$. 

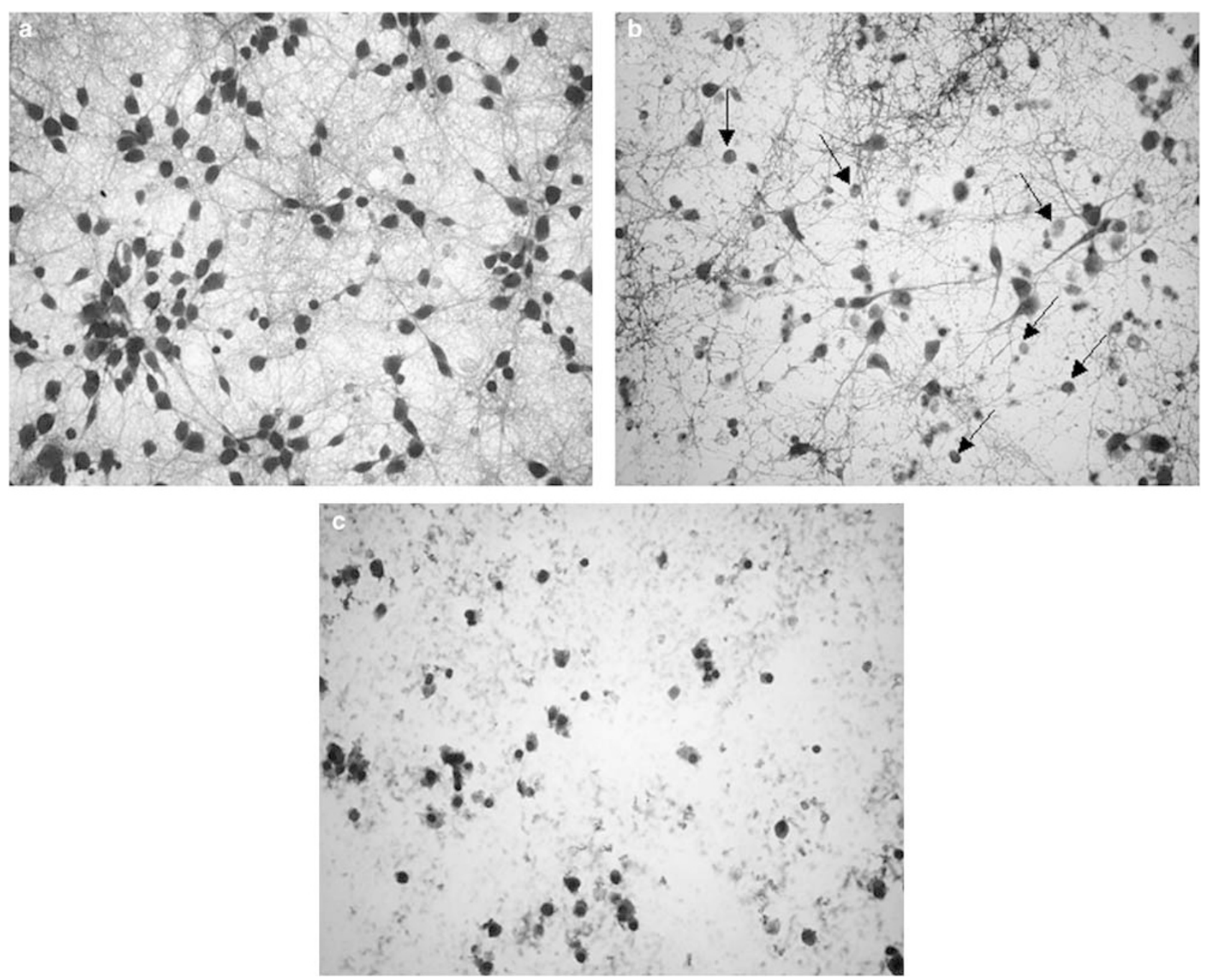

Figure 9 Photomicrographs of cultured neurons stained with May/Grunwald-Geimsa. (a) Control neuronal cultures show clusters of cells with a large network of cell processes. (b) Neurons treated with $\mathrm{CuSO}_{4}(10 \mu \mathrm{M})$ for $14 \mathrm{~h}$ show loss of clustering, reduction in the number of cells and the presence of necrotic cells characterized by pallor and cell shrinkage (arrows). (c) Neurons treated with $\mathrm{CuSO}_{4}(20 \mu \mathrm{M})$ for $14 \mathrm{~h}$ show a greater extent of cell loss and disintegration.

Astrocyte death by copper was in part mediated by $\mathrm{mPT}$ as documented by the ability of CsA to significantly (41\%) block astrocyte cell death. Death occurring as a consequence of $\mathrm{mPT}$ is likely due to the collapse of the $\Delta \Psi \mathrm{m}$ which uncouples the respiratory chain thereby resulting in energy failure. $^{45,46}$ The present study demonstrating a reduction of ATP levels by copper supports the involvement of energy failure in astrocyte death.

Another means by which copper may cause cell death is OS. ${ }^{21,22,47,48}$ Our observation that PBN, which is known to trap several free radical species, including superoxide, ${ }^{49}$ significantly blocked astrocyte death suggests that multiple species of free radicals produced by copper play a role in astrocyte death. In addition, the fact that vitamin E blocked cell death by copper suggests that lipid peroxidation represents one mechanism by which OS results in cell death. Similarly, the ability of DFX, an iron chelator, to block astrocyte death implies the involvement of iron-mediated hydroxyl radicals in such cell death. Nevertheless, other mechanisms of neuroprotection by DFX have been proposed, such as the upregulation of hypoxia-inducible factor- $1 \alpha$ (HIF1- $\alpha$ ) in oxygen-glucose deprivation. ${ }^{50}$ Whether a similar protective role of HIF1- $\alpha$ by DFX occurs in copper toxicity is not known.

Despite antioxidants significantly blocking copper-induced cell death, our study failed to observe protein oxidation (carbonylation) by copper, although OS did contribute to PTN (see below). One possibility for a failure to detect oxidation of proteins might be due to a rapid degradation of oxidized proteins by the proteosomal system. Consistent with this view, the activation of the proteosomes by OS has been reported. ${ }^{51}$ Similarly, enhanced proteosomal activity by OS has been shown in cultured astrocytes exposed to toxic levels of ammonia. ${ }^{52}$ Alternatively, copper might be 


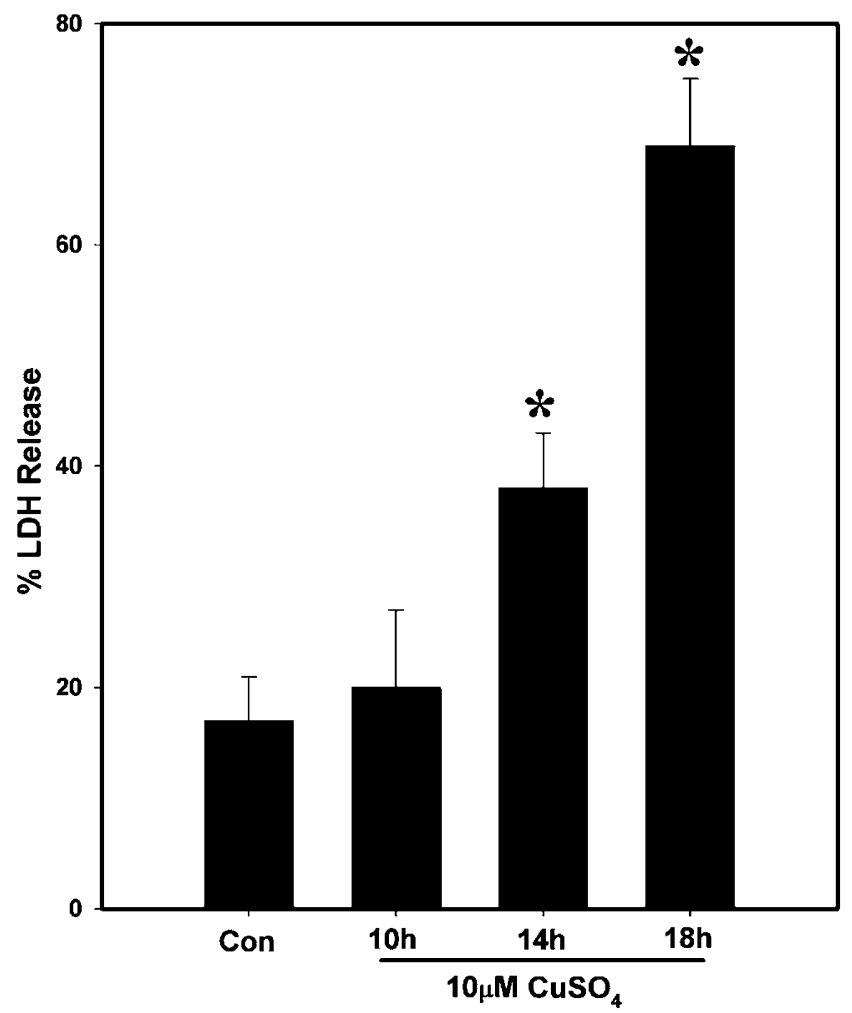

Figure 10 Time course of LDH release after $\mathrm{CuSO}_{4}$ treatment in cultured neurons. ${ }^{*} P<0.01$ vs control. causing greater oxidative damage to membrane lipids and nucleic acids rather than to proteins. The latter possibility is consistent with reports documenting copper-induced lipid peroxidation and associated cell death in neurons and glioma cells. ${ }^{47,48}$ Our observation that vitamin E blocked copper-induced cell death in astrocytes is consistent with the above reports. Copper has also been shown to cause DNA damage and cell death in brain in an animal model of Wilson's disease. Additional studies will be required to better establish the role of protein oxidation in neural cell injury by copper.

Copper caused significant PTN by 24 and $48 \mathrm{~h}$ exposure, suggesting the involvement of nitrosative stress in copper toxicity. The NOS inhibitors L-NAME and aminoguanidine both significantly blocked copper-induced astrocyte death and $\mathrm{mPT}$, consistent with the upregulation of iNOS by copper. ${ }^{38}$ As PTN appears to be mediated by peroxynitrite, which is formed by the reaction of NO with superoxide, ${ }^{53}$ our observations of copper-induced PTN invokes OS in PTN. As peroxynitrite can result in cell death in astrocytes, ${ }^{54-56}$ PTN may represent an important factor by which copper results in cell death.

CsA significantly blocked copper-mediated PTN in astrocytes, highlighting the important role of $\mathrm{mPT}$ in PTN. Although it is precisely not known how mPT contributes to PTN formation, mitochondria have been shown to produce
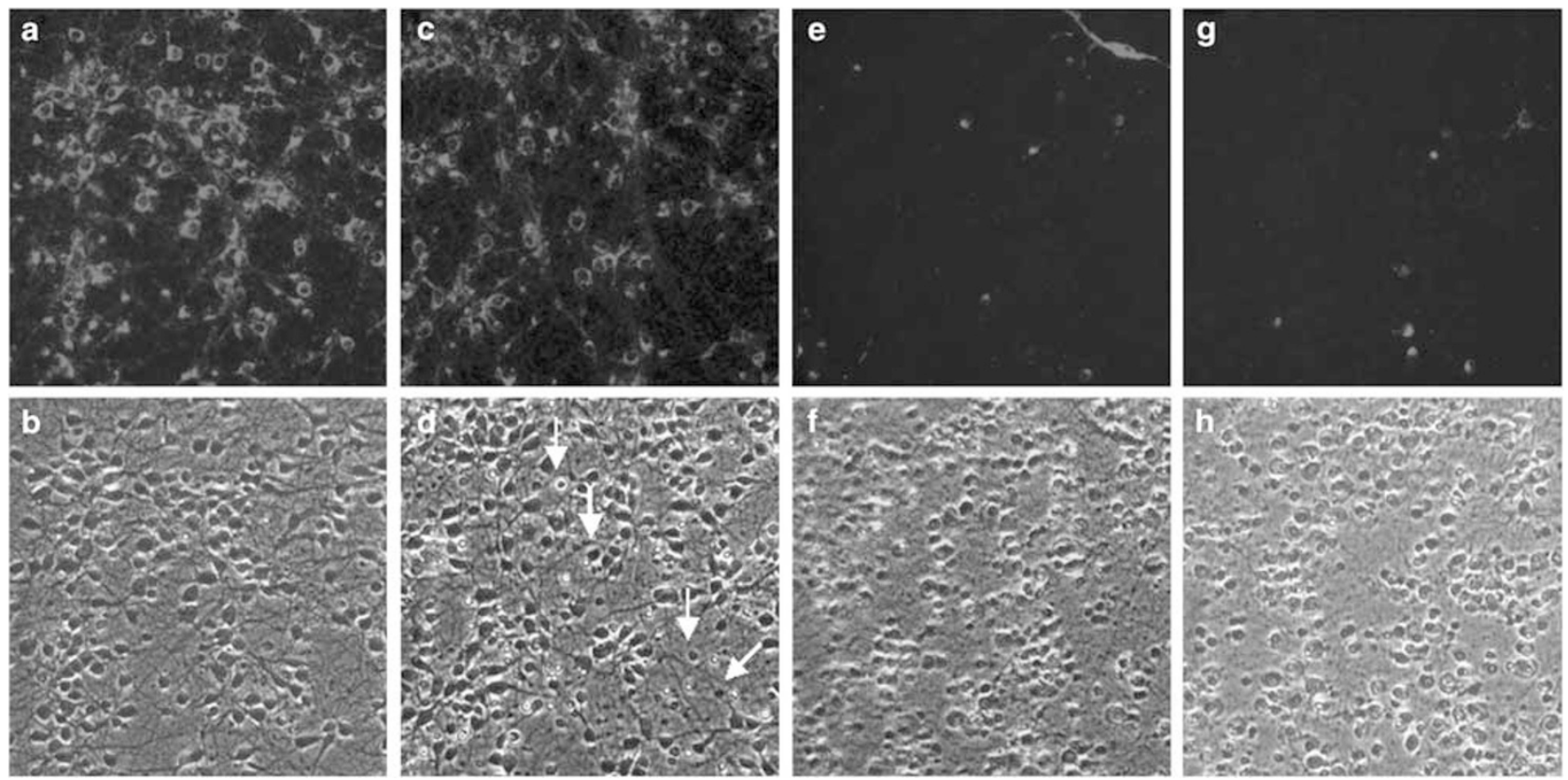

Figure 11 Effect of copper on TMRE fluorescence in cultured neurons. (a, c, e, g) Represent TMRE fluorescent images, whereas (b, d, f, h) represent corresponding phase contrast images. (a) Control neurons show TMRE fluorescence consistent with an intact $\Delta \Psi \mathrm{m}$. (b) Phase contrast image of control neurons showing intact cellular processes. (c) Neurons $14 \mathrm{~h}$ after copper $(10 \mu \mathrm{M})$ exposure shows fluorescence in fewer cells. (d) Copper treatment displays focal neuronal injury as indicated by the presence of shrunken cell bodies and pyknotic nuclei (arrows). (e) Marked loss of TMRE fluorescence is evident in neurons $18 \mathrm{~h}$ post-copper treatment. (f) Death of neurons is noted characterized by shrunken cell bodies and complete loss of cell processes. (g) CsA failed to protect against the loss of the $\Delta \Psi \mathrm{m}$ due to copper (18h). (h) Similarly, CsA had no protective effect against cell injury. 

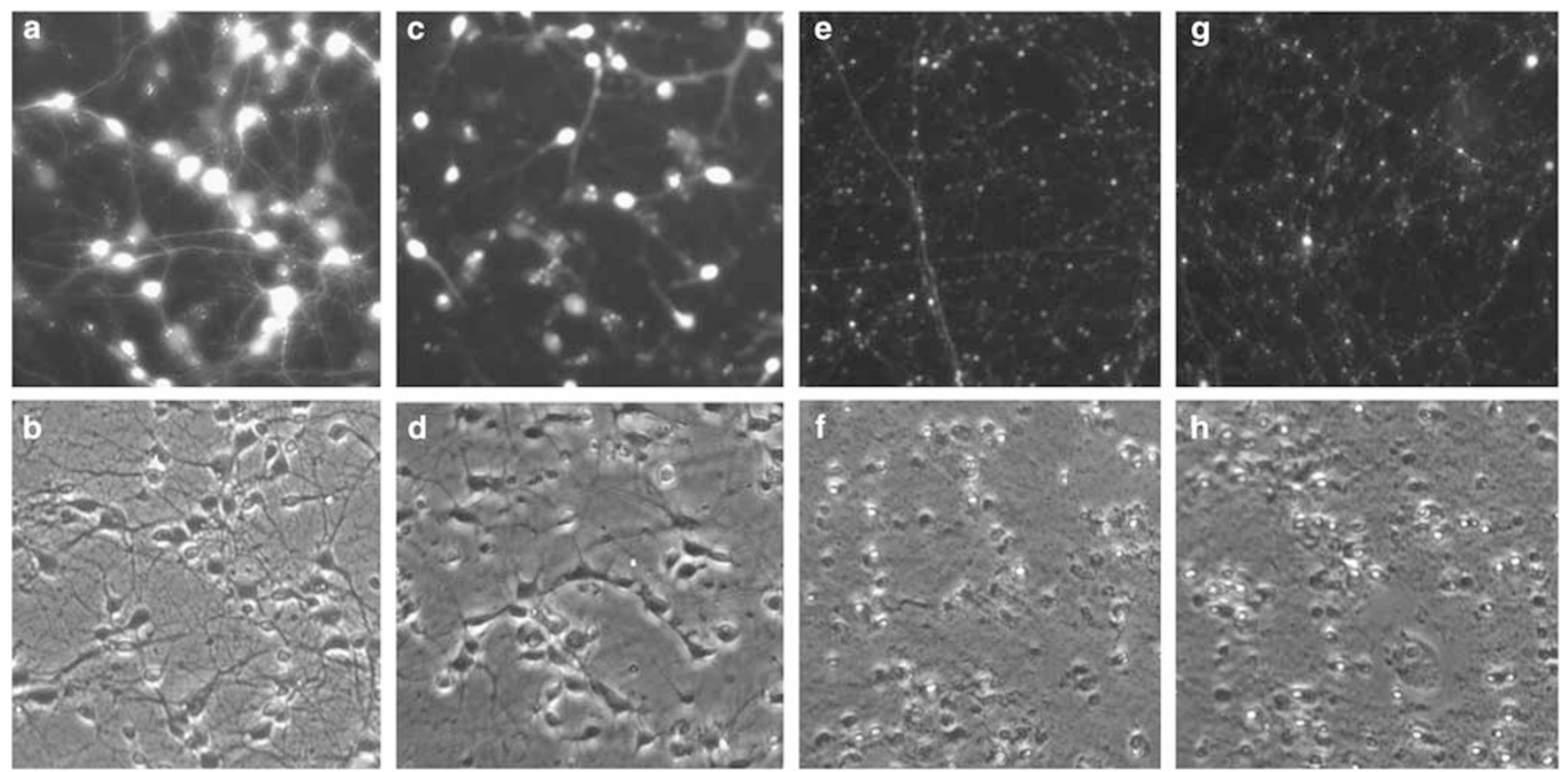

Figure 12 Effect of copper on mitochondrial permeability using the calcein/cobalt method. (a, c, e, g) Represent calcein fluorescent images whereas $(\mathbf{b}, \mathbf{d}, \mathbf{f}, \mathbf{h})$ represent corresponding phase contrast images. (a) Control neurons show bright calcein fluorescence consistent with the intact $\Delta \Psi \mathrm{m}$. (b) Phase contrast image of control neurons showing intact cell processes. (c) Neurons treated with copper $(10 \mu \mathrm{M})$ for $14 \mathrm{~h}$ exhibit calcein fluorescence similar to that of control neurons but such fluorescence was detected in fewer cells. (d) A reduction in the number of neurons is noted. (e) Neurons treated with copper for $18 \mathrm{~h}$ show an extensive reduction in calcein fluorescence. (f) The micrograph illustrates loss of cell processes and shrunken cell bodies. (g) Cells treated with CsA did not restore the loss of calcein fluorescence after $18 \mathrm{~h}$ of copper exposure. (h) Treatment with CsA failed to show any cytoprotection.

reactive oxygen species (ROS), as well as $\mathrm{NO},{ }^{57}$ and induction of $\mathrm{mPT}$ has been suggested as one mechanism for such mitochondrial ROS and NO generation. ${ }^{58,59}$ Moreover, as peroxynitrite, largely generated in mitochondria, is the major free radical responsible for PTN ${ }^{53}$ it is likely that superoxide and NO produced by mPT might lead to PTN. Consistent with this view, Burke et $a l^{60}$ have shown blockade of PTN by CsA in mouse hepatocytes exposed to chloroform. Collectively, mPT may be an important source of NO leading to nitrosative stress-mediated cell injury.

In contrast to astrocytes, copper resulted in early and severe neuronal injury/death, which was blocked by antioxidants, suggesting that OS represents an important mechanism in neuronal death. As noted above, copper is well known to cause oxidative and nitrosative stress (ONS). ${ }^{21,22,38,47,48}$ Copper has also been shown to deplete glutathione levels in cultured neurons, ${ }^{47}$ an event likely to aggravate OS and neuronal death.

OS induced by copper in neurons has been shown to inactivate several mitochondrial enzymes resulting in severe ATP loss. ${ }^{22,61}$ Although a similar degree of oxidative and nitrosative protein adducts by copper was observed in astrocytes and neurons, copper caused an early and a far greater degree of cell death in neurons than in astrocytes. The reason for higher vulnerability of neurons to injury than astrocytes might be due to greater sensitivity of neuronal mitochondria to copper as compared to astrocytic mi- tochondria. However, as noted above, the extent of lipid peroxidation and nucleic acid oxidation is not known and possibly damage to these macromolecules may explain the differential response. The observation that copper results in a greater degree of ATP loss (63\%) in neurons than astrocytes $(32 \%)$ is consistent with the view that mitochondria are selective targets for neuronal damage by copper. Such higher sensitivity of neurons in copper toxicity is consistent with the severe neuronal loss documented in patients with Wilson's disease. $^{62}$

In contrast to astrocytes, $\mathrm{mPT}$ was not identified in cultured neurons at any time point after exposure of cultures to copper (3-18 h). Although we observed complete absence of TMRE and calcein fluorescence in neurons $18 \mathrm{~h}$ after copper treatment, such loss of fluorescence was due to severe injury/death of neurons as documented by cytopathology as well as by LDH release. Parallel observations of TMRE images with phase contrast microscopy showed that loss of fluorescence correlated with the presence of neuronal injury/death (Figure 10). Failure to document a transient induction of mPT by copper at early time points can be reasonably excluded as the cultures were carefully monitored for any loss in TMRE, and calcein fluorescence throughout the first $18 \mathrm{~h}$ of treatment. Failure to identify $\mathrm{mPT}$ in neurons is consistent with earlier observations demonstrating that copper does not result in dissipation of the $\Delta \Psi \mathrm{m}$ in cultured neurons. ${ }^{63}$ 


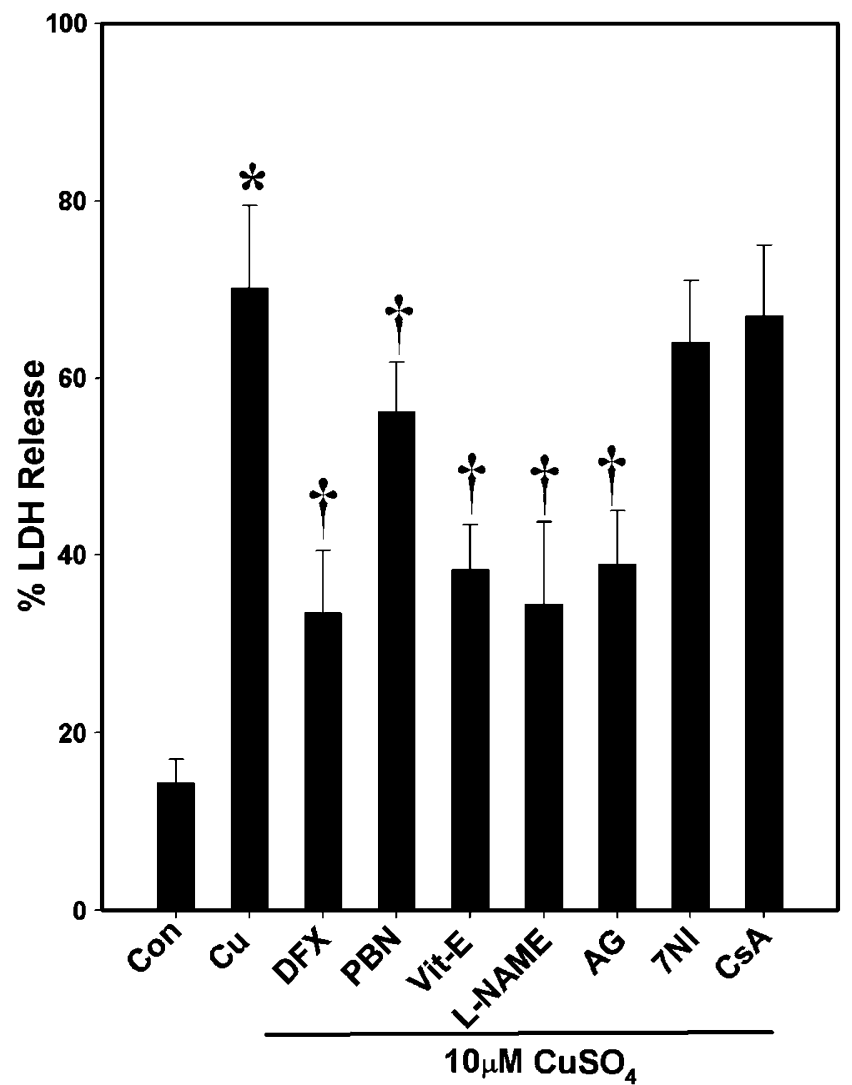

Figure 13 Effect of antioxidants and nitric oxide synthase inhibitors on copper-induced cell death in cultured neurons. Neurons treated with $\mathrm{CuSO}_{4}$ $(10 \mu \mathrm{M})$ for $18 \mathrm{~h}$ showed $68 \% \mathrm{LDH}$ release. Pretreatment of cultures with different antioxidants significantly reduced the extent of $\mathrm{LDH}$ release. ${ }^{*} P<0.01$ vs control and ${ }^{\dagger} P<0.01-0.05$ vs $\mathrm{CuSO}_{4}$. CsA and 7-NI did had no effect.

The reason for the absence of $\mathrm{mPT}$ in neurons as compared to astrocytes is not known. However, mitochondrial heterogeneity between neurons and astrocytes is well established. ${ }^{64-66}$ Such heterogeneity involves the differential distribution of enzymes of the tricarboxylic acid cycle, as well as differences with respect to glutamate metabolism. ${ }^{64,67}$ Heterogeneity between astrocytes and neurons also exists with regard to the sensitivity of these cells to the $\mathrm{Ca}^{2+}$-induced $\mathrm{mPT}$, as a CsA-sensitive decline in $\Delta \Psi \mathrm{m}$ by $\mathrm{Ca}^{2+}$ has been documented in astrocyte mitochondria, whereas a similar event was not observed in neurons. ${ }^{68,69}$ Such differences in sensitivity may possibly explain the differential response of neurons and astrocytes to the induction of $\mathrm{mPT}$ by copper.

In summary, our studies demonstrate that copper induces $\mathrm{mPT}$ in cultured astrocytes but not in neurons. The copperinduced $\mathrm{mPT}$ caused a delayed death in astrocytes, which was attenuated by CsA as well as by antioxidants and NOS inhibitors. In neurons, copper caused early and extensive cell death, which was prevented by antioxidants and NOS inhibitors, whereas CsA had no protective effect. These

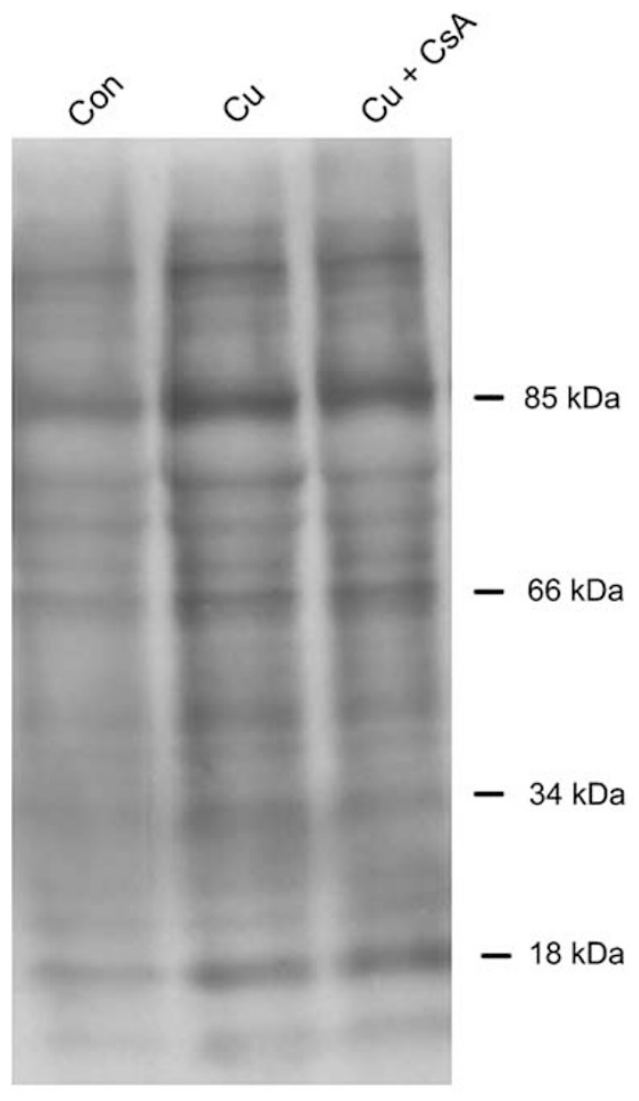

Tubulin

Figure 14 Effect of copper on protein tyrosine nitration in cultured neurons. Copper caused increased tyrosine nitration of proteins in the range of $18-85 \mathrm{kDa}$. CsA had no effect.

findings suggest that ONS and $\mathrm{mPT}$ represent critical components in the mechanisms of copper-induced neural cell injury.

\section{ACKNOWLEDGEMENT}

This work was supported by the Department of Veterans Affairs Merit Review and by NIH Grant No. DK063311. KVR is the recipient of grant from The American Liver Foundation. We greatly appreciate the guidance of $\mathrm{Dr}$ AR Jayakumar in the protein oxidation and nitration studies. The technical assistance of Alina Fernandez is greatfully acknowledged.

1. Tainer JA, Getzoff ED, Richardson JS, et al. Structure and mechanism of copper, zinc superoxide dismutase. Nature 1983;306:284-287.

2. Linder MC, Hazegh-Azam M. Copper biochemistry and molecular biology. Am J Clin Nutr 1996;63:797S-811S.

3. Nalbandyan RM. Copper in brain. Neurochem Res 1983;8:1211-1232.

4. Waggoner DJ, Bartnikas TB, Gitlin JD. The role of copper in neurodegenerative disease. Neurobiol Dis 1999;6:221-230.

5. Perry G, Sayre LM, Atwood CS, et al. The role of iron and copper in the aetiology of neurodegenerative disorders: therapeutic implications. CNS Drugs 2002;16:339-352.

6. Bush Al. Metals and neuroscience. Curr Opin Chem Biol 2000;4: 184-191.

7. Brown DR. Copper and prion diseases. Biochem Soc Trans 2002;30: 742-745. 
8. Donnelly PS, Xiao Z, Wedd AG. Copper and Alzheimer's disease. Curr Opin Chem Biol 2007;11:128-133.

9. Brown DR. Interactions between metals and alpha-synuclein-function or artefact? FEBS J 2007;274:3766-3774.

10. Ma KC, Ye ZR, Fang J, et al. Glial fibrillary acidic protein immunohistochemical study of Alzheimer I \& II astrogliosis in Wilson's disease. Acta Neurol Scand 1988;78:290-296.

11. Ala A, Walker AP, Ashkan K, et al. Wilson's disease. Lancet 2007;369:397-408.

12. Bertrand E, Lechowicz W, Szpak GM, et al. Quantitative study of pathological forms of astroglia in Wilson's disease. Folia Neuropathol 1997:35:227-232.

13. Brewer GJ. Copper in medicine. Curr Opin Chem Biol 2003;7:207-212.

14. Shimoji A, Miyakawa T, Watanabe K, et al. Wilson's disease with extensive degeneration of cerebral white matter and cortex. Jpn J Psychiatry Neurol 1987;41:709-717.

15. Zhu X, Su B, Wang $X$, et al. Causes of oxidative stress in Alzheimer disease. Cell Mol Life Sci 2007:64:2202-2210.

16. Gutteridge JM, Wilkins S. Copper salt-dependent hydroxyl radical formation. Damage to proteins acting as antioxidants. Biochim Biophys Acta 1983;759:38-41.

17. Gunther MR, Hanna PM, Mason RP, et al. Hydroxyl radical formation from cuprous ion and hydrogen peroxide: a spin-trapping study. Arch Biochem Biophys 1995;316:515-522.

18. Multhaup G, Schlicksupp A, Hesse L, et al. The amyloid precursor protein of Alzheimer's disease in the reduction of copper(II) to copper(I). Science 1996;271:1406-1409.

19. Dizdaroglu M, Rao G, Halliwell B, et al. Damage to the DNA bases in mammalian chromatin by hydrogen peroxide in the presence of ferric and cupric ions. Arch Biochem Biophys 1991;285:317-324.

20. Sokol RJ, Twedt D, McKim JM, et al. Oxidant injury to hepatic mitochondria in patients with Wilson's disease and Bedlington terriers with copper toxicosis. Gastroenterology 1994;107:1788-1798.

21. Ferretti G, Bacchetti T, Moroni C, et al. Copper-induced oxidative damage on astrocytes: protective effect exerted by human high density lipoproteins. Biochim Biophys Acta 2003;1635:48-54.

22. Sheline CT, Choi EH, Kim-Han JS, et al. Cofactors of mitochondrial enzymes attenuate copper-induced death in vitro and in vivo. Ann Neurol 2002;52:195-204.

23. Zoratti M, Szabo I. The mitochondrial permeability transition. Biochim Biophys Acta 1995;1241:139-176.

24. Bernardi P. The permeability transition pore. Control points of a cyclosporin A-sensitive mitochondrial channel involved in cell death. Biochim Biophys Acta 1996;1275:5-9.

25. Broekemeier KM, Dempsey ME, Pfeiffer DR. Cyclosporin A is a potent inhibitor of the inner membrane permeability transition in liver mitochondria. J Biol Chem 1989;264:7826-7830.

26. Ducis I, Norenberg LO, Norenberg MD. The benzodiazepine receptor in cultured astrocytes from genetically epilepsy-prone rats. Brain Res 1990;531:318-321.

27. Juurlink BH, Hertz L. Plasticity of astrocytes in primary cultures: an experimental tool and a reason for methodological caution. Dev Neurosci 1985;7:263-277.

28. Hertz L, Matz H. Inhibition of adenosine deaminase activity reveals an intense active transport of adenosine into neurons in primary cultures. Neurochem Res 1989;14:755-760.

29. Stuerenburg HJ. CSF copper concentrations, blood-brain barrier function, and coeruloplasmin synthesis during the treatment of Wilson's disease. J Neural Transm 2000;107:321-329.

30. Kodama H, Okabe I, Yanagisawa M, et al. Does CSF copper level in Wilson disease reflect copper accumulation in the brain? Pediatr Neurol 1988;4:35-37.

31. Wroblewski F, Ladue JS. Lactic dehydrogenase activity in blood. Proc Soc Exp Biol Med 1955;90:210-213.

32. Hazell AS, Norenberg MD. Manganese decreases glutamate uptake in cultured astrocytes. Neurochem Res 1997;22:1443-1447.

33. Rao KV, Norenberg MD. Manganese induces the mitochondrial permeability transition in cultured astrocytes. J Biol Chem 2004;279:32333-32338.

34. Petronilli V, Miotto G, Canton M, et al. Transient and long-lasting openings of the mitochondrial permeability transition pore can be monitored directly in intact cells by changes in mitochondrial calcein fluorescence. Biophys J 1999;76:725-734.
35. Halestrap AP, Woodfield KY, Connern CP. Oxidative stress, thiol reagents, and membrane potential modulate the mitochondrial permeability transition by affecting nucleotide binding to the adenine nucleotide translocase. J Biol Chem 1997;272: 3346-3354.

36. Kowaltowski AJ, Castilho RF, Vercesi AE. Mitochondrial permeability transition and oxidative stress. FEBS Lett 2001;495:12-15.

37. Rama Rao KV, Jayakumar AR, Norenberg MD. Role of oxidative stress in the ammonia-induced mitochondrial permeability transition in cultured astrocytes. Neurochem Int 2005;47:31-38.

38. Cuzzocrea S, Persichini T, Dugo L, et al. Copper induces type II nitric oxide synthase in vivo. Free Radic Biol Med 2003;34: 1253-1262.

39. Hortelano S, Dallaporta B, Zamzami N, et al. Nitric oxide induces apoptosis via triggering mitochondrial permeability transition. FEBS Lett 1997:410:373-377.

40. Piantadosi CA, Tatro LG, Whorton AR. Nitric oxide and differential effects of ATP on mitochondrial permeability transition. Nitric Oxide 2002;6:45-60.

41. Gyulkhandanyan AV, Feeney CJ, Pennefather PS. Modulation of mitochondrial membrane potential and reactive oxygen species production by copper in astrocytes. J Neurochem 2003;87:448-460.

42. Garcia N, Martinez-Abundis E, Pavon N, et al. Copper induces permeability transition through its interaction with the adenine nucleotide translocase. Cell Biol Int 2007;31:893-899.

43. Krumschnabel G, Manzl C, Berger C, et al. Oxidative stress, mitochondrial permeability transition, and cell death in Cu-exposed trout hepatocytes. Toxicol Appl Pharmacol 2005;209:62-73.

44. Chen SH, Lin JK, Liu SH, et al. Apoptosis of cultured astrocytes induced by the copper and neocuproine complex through oxidative stress and JNK activation. Toxicol Sci 2008;102:138-149.

45. Zamzami N, Larochette N, Kroemer G. Mitochondrial permeability transition in apoptosis and necrosis. Cell Death Differ 2005;12(Suppl 2): 1478-1480.

46. Kroemer G, Galluzzi L, Brenner C. Mitochondrial membrane permeabilization in cell death. Physiol Rev 2007;87:99-163.

47. White AR, Bush Al, Beyreuther K, et al. Exacerbation of copper toxicity in primary neuronal cultures depleted of cellular glutathione. J Neurochem 1999;72:2092-2098.

48. Merker K, Hapke D, Reckzeh K, et al. Copper related toxic effects on cellular protein metabolism in human astrocytes. Biofactors 2005:24:255-261.

49. Jenkins CA, Murphy DM, Rowlands CC, et al. EPR study of spin-trapped free radical intermediates formed in the heterogeneously-assisted photodecomposition of acetaldehyde. J Chem Soc. Perkin Transactions 1997;2:2479-2485.

50. Hamrick SE, McQuillen PS, Jiang $X$, et al. A role for hypoxia-inducible factor-1alpha in desferoxamine neuroprotection. Neurosci Lett 2005;379:96-100.

51. Breusing N, Grune T. Regulation of proteasome-mediated protein degradation during oxidative stress and aging. Biol Chem 2008;389:203-209.

52. Widmer R, Kaiser B, Engels $M$, et al. Hyperammonemia causes protein oxidation and enhanced proteasomal activity in response to mitochondria-mediated oxidative stress in rat primary astrocytes. Arch Biochem Biophys 2007;464:1-11.

53. Turko IV, Murad F. Protein nitration in cardiovascular diseases. Pharmacol Rev 2002;54:619-634.

54. Amin N, Pearce B. Peroxynitrite-induced toxicity in cultured astrocytes. Brain Res 1997;773:227-230.

55. Zhang $\mathrm{Y}$, Wang $\mathrm{H}$, Li J, et al. Peroxynitrite-induced neuronal apoptosis is mediated by intracellular zinc release and 12-lipoxygenase activation. J Neurosci 2004:24:10616-10627.

56. Muyderman $\mathrm{H}$, Wadey AL, Nilsson $\mathrm{M}$, et al. Mitochondrial glutathione protects against cell death induced by oxidative and nitrative stress in astrocytes. J Neurochem 2007;102:1369-1382.

57. Zorov DB, Bannikova SY, Belousov VV, et al. Reactive oxygen and nitrogen species: friends or foes? Biochemistry (Mosc) 2005;70:215-221.

58. Zorov DB, Juhaszova M, Sollott SJ. Mitochondrial ROS-induced ROS release: an update and review. Biochim Biophys Acta 2006;1757:509-517.

59. Plotnikov EY, Kazachenko AV, Vyssokikh MY, et al. The role of mitochondria in oxidative and nitrosative stress during ischemia/ reperfusion in the rat kidney. Kidney Int 2007;72:1493-1502. 
60. Burke AS, Redeker K, Kurten RC, et al. Mechanisms of chloroforminduced hepatotoxicity: oxidative stress and mitochondrial permeability transition in freshly isolated mouse hepatocytes. J Toxicol Environ Health A 2007;70:1936-1945.

61. Sheline CT, Wei L. Free radical-mediated neurotoxicity may be caused by inhibition of mitochondrial dehydrogenases in vitro and in vivo. Neuroscience 2006;140:235-246.

62. Duchen $L$, Jacobs JM. Nutritional deficiencies and metabolic disorders. In: Adams JH, Duchen LW (eds). Greenfield's Neuropathology. Oxford Press: New York, 1992, pp 811-880.

63. Sheline CT, Choi DW. Cu2+ toxicity inhibition of mitochondrial dehydrogenases in vitro and in vivo. Ann Neurol 2004;55: 645-653.

64. Sonnewald U, Hertz L, Schousboe A. Mitochondrial heterogeneity in the brain at the cellular level. J Cereb Blood Flow Metab 1998;18: 231-237.
65. Kristian $\mathrm{T}$, Weatherby $\mathrm{TM}$, Bates $\mathrm{TE}$, et al. Heterogeneity of the calcium-induced permeability transition in isolated non-synaptic brain mitochondria. J Neurochem 2002;83:1297-1308.

66. Huang HM, Fowler $\mathrm{C}$, Zhang $\mathrm{H}$, et al. Mitochondrial heterogeneity within and between different cell types. Neurochem Res 2004;29: 651-658.

67. Sonnewald U, White LR, Odegard E, et al. MRS study of glutamate metabolism in cultured neurons/glia. Neurochem Res 1996;21: 987-993.

68. Fiskum G, Chandrasekaran K, Mehrabyan Z, et al. Differential invovement of permeability transition in $\mathrm{Ca}^{2+}$-induced alterations to mitochondria within cultured neurons and astrocytes. J Neurochem 2000;74:S95.

69. Bambrick LL, Chandrasekaran K, Mehrabian Z, et al. Cyclosporin A increases mitochondrial calcium uptake capacity in cortical astrocytes but not cerebellar granule neurons. J Bioenerg Biomembr 2006;38:43-47. 